total dry matter of the growing-finishing diet. No significant difference was observed between the different groups in growth performance or mean carcass composition. In a second experiment made in metabolism crates, two extreme crude fibre contents were tested. It was confirmed that the digestible energy contents of the complete diets were similar i.e. 3790 and $3700 \mathrm{kcal} / \mathrm{kg} \mathrm{D.M.} \mathrm{The} \mathrm{apparent} \mathrm{digestibility} \mathrm{of} \mathrm{energy} \mathrm{and} \mathrm{protein}$ decreased by 2.3 and 2.7 points per point of increase in the crude fibre content, while that of fat did not change and that of the parietal components tended to increase. In this trial the digestible energy value of whey was estimated to be $3490 \mathrm{kcal} / \mathrm{kg}$ D.M.

Under the same feeding conditions we thereafter compared dried grass to whole maize flour, oats chaff and apple distiller's residues (all exhibiting a high crude fibre content, i.e. 6 p. 100). Four groups of 12 piglets $(24 \mathrm{~kg}$ live weight) $\mathrm{kept}$ in individual pens were used. In the growing as in the finishing period dried grass and apple distiller's residues led to significantly better results than the other two crude fibre sources, but there was no significant difference in the carcass composition of the four groups. Differences in the growth performance may be related to the much higher hemicellulose contents of whole maize flour and oats chaff. These results show that the extrapolation of Kirchgessner and Schneider's equation to other sources of crude fibre than that of cereals for which it had been calculated, may lead to erroneous results. In practice, grass flour and apple distiller's residues seem to be good sources of crude fibre to supplement whey in growing-finishing pig diets.

\title{
Restricted supply of a feed supplement and ad libitum feeding of maize or barley Influence of various factors
}

\author{
J. LOUGNON \\ A.E.C. (Service Développement Alimentation animale), F 03600 Commentry
}

\begin{abstract}
Ninety-six individually housed and fed female pigs weighing $20 \mathrm{~kg}$, were used in this experiment.

The animals were offered maize (M) or barley (B) ad libitum. In each case they received a restricted feed supplement containing soybean meal (S) or soybean meal supplemented with lysine (SL). This feed was offered according to two modalities : either once a day (rhythm A) or in double quantity, once every two days (rhythm B). The experiment involved two groups of animals and two periods, the first one from January to June, the second one from July to December.
\end{abstract}

All parameters (feed intake - growth rate - feed efficiency - body conposition) were affected by the kind of cereal used. The consumption of barley exceeded by $15 \mathrm{p} .100$, on an average, that of maize. The pigs fed on maize showed a better feed conversion ratio, but they were fatter.

The performance were almost similar in the pigs receiving feed supplement S or SL (the lysine supply of which was comparable).

The feeding rhythm (A or B) of this feed supplement did not affect the results. Opposite to that, the period of the year had an influence as revealed by the different results of the two experimental series. Thus, pigs fattened mainly in the Summer consumed less cereal (and therefore energy) and exhibited a lower growth-rate and leaner carcasses. 